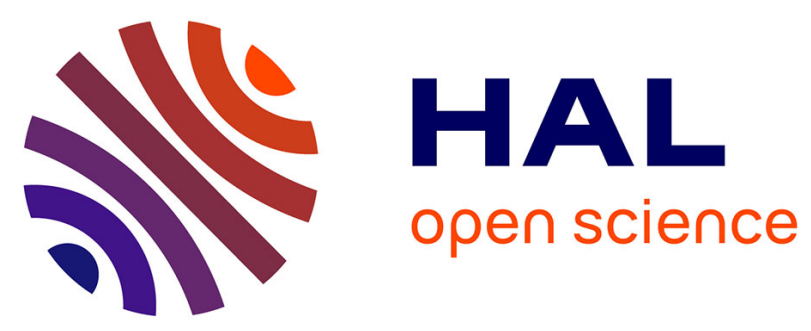

\title{
Direct vs. standard method of insertion of an intrauterine contraceptive device: insertion pain and outcomes at 6 months
}

Aurore Bastin, Alexandre Scanff, Stephane Fraize, Jean-Christophe Hild, Maela Le Lous, Vincent Lavoue, Yannick Ruelle, Samah Chaaban

\section{To cite this version:}

Aurore Bastin, Alexandre Scanff, Stephane Fraize, Jean-Christophe Hild, Maela Le Lous, et al.. Direct vs. standard method of insertion of an intrauterine contraceptive device: insertion pain and outcomes at 6 months. European Journal of Contraception and Reproductive Health Care, 2019, 24 (5), pp.399406. 10.1080/13625187.2019.1659951 . hal-02303717

\section{HAL Id: hal-02303717 https://hal-univ-rennes1.archives-ouvertes.fr/hal-02303717}

Submitted on 3 Dec 2019

HAL is a multi-disciplinary open access archive for the deposit and dissemination of scientific research documents, whether they are published or not. The documents may come from teaching and research institutions in France or abroad, or from public or private research centers.
L'archive ouverte pluridisciplinaire HAL, est destinée au dépôt et à la diffusion de documents scientifiques de niveau recherche, publiés ou non, émanant des établissements d'enseignement et de recherche français ou étrangers, des laboratoires publics ou privés. 
Direct vs standard method of insertion of an intrauterine contraceptive device: insertion pain and outcomes at 6 months

Aurore Bastin ${ }^{\mathrm{a}}$, Alexandre Scanff ${ }^{\mathrm{b}}$, Stéphane Fraize ${ }^{\mathrm{c}}$, Jean-Christophe Hild ${ }^{\mathrm{d}}$, Maela Le Lous ${ }^{\mathrm{e}}$, Vincent Lavoue e,f,g, Yannick Ruelle ${ }^{\mathrm{f}}$ and Samah Chaaban ${ }^{\mathrm{g}}$

andependent researcher, Locmiquelic, France; bepartment of Epidemiology and Public Health, Rennes University Hospital, Rennes, France; 'Independent researcher, Saint-Caprais-de-Bordeaux, France; ${ }^{\mathrm{d} I n d e p e n d e n t ~ r e s e a r c h e r, ~ P l o e m e u r, ~ F r a n c e ; ~}{ }^{e}$ Department of Gynaecology, Rennes University Hospital, Rennes, France; ${ }^{\mathrm{f}}$ Medical School, University of Rennes 1, Rennes, France; ${ }^{\mathrm{g}}$ Inserm U1242, Rennes, France; ${ }^{\mathrm{f}}$ Department of General Practice, UFR SMBH, University of Paris 13, Bobigny, France; ㄴa Case de Santé, Toulouse, France

\section{CONTACT}

Aurore Bastin, 15 rue du Port, 56570 Locmiquelic, France

aurore.bastin1@gmail.com 


\section{ABSTRACT}

Objectives: The direct method is a procedure designed to cause less pain during insertion of an intrauterine contraceptive device (IUCD). It was first reported in 2005 and differs from the standard method of insertion recommended by IUCD manufacturers. In France, the direct method is well known and used by experienced practitioners, but it has never been evaluated against the standard method of insertion. The aim of the study was therefore to compare the direct method with the standard method in terms of pain experienced during insertion and the side effects and satisfaction rates over 6 months.

Methods: A prospective observational study was conducted in France between June and December 2016 to compare the direct and standard methods of IUCD insertion.

Results: The study included 535 women: 281 in the direct method group (DM group) and 254 in the standard method group (SM group). Women in the DM group reported less pain. This difference was assessed by multilevel multivariate analysis $(-8.3 \mathrm{~mm}, 95 \%$ confidence interval $[\mathrm{CI}]-14.3,-2.3)$. There was no difference in the occurrence of infection (1.4\% vs $2.8 \% ; p=0.366)$ and 6 month continuation rates (89.4\% vs $89.2 \%$; $p=0.936)$. Satisfaction rates at 6 months were higher in the DM group (93.6\% vs $87.4 \% ; p=0.019$ ).

Conclusion: The results of the study suggest that the direct method of IUCD insertion is associated with less pain and does not increase the risk of adverse effects. Widespread adoption of the direct method could improve women's comfort and lead to a higher uptake of the IUCD as a form of contraception.

\section{KEYWORDS}

Direct method; insertion; intrauterine contraceptive device; IUD; pain; standard method 


\section{Introduction}

Intrauterine contraceptive devices (IUCDs), including the copper-bearing intrauterine device (IUD) and the levonorgestrel-releasing intrauterine system (LNG-IUS), are highly effective methods of contraception and are associated with low complication rates [1-3]. Concerns about insertion pain may, however, be a potential barrier to their use as first-line contraception [4,5]. A study on IUD insertion showed that $>50 \%$ of women experienced pain on insertion, with $11 \%$ scoring $\geq 50 \mathrm{~mm}$ on a $100 \mathrm{~mm}$ visual analogue scale (VAS) [6]. Reported mean VAS values vary between 40 and 60 $\mathrm{mm}$, with greater pain experienced by nulliparous women [6-11].

International recommendations suggest prescribing painkillers before the procedure but do not specify the molecule or the dosage [2,3,12]. Previous studies show contradictory findings for naproxen, tramadol and lidocaine in pain reduction during IUCD insertion, and misoprostol and other non-steroidal anti-inflammatory drugs (NSAIDs) have been found to be ineffective [13-15]. Pain management thus remains an area of improvement for women undergoing IUCD insertion.

An experimental insertion method aimed at causing less pain was described in France in 2005 [16]. The method is called the 'torpedo method', 'plunging insertion' or the 'direct method' and can be used with T-shaped IUCDs (including the LNG-IUS). In the direct method, the inserter is introduced up to the internal cervical os (marked by resistance or an insertion depth of 3-4 cm), without passing through it, and the device is then propelled into the uterine cavity. This contrasts with the standard method, where the inserter is placed up to the uterine fundus. The purpose of the direct method technique is to facilitate insertion and avoid the pain caused by the inserter (which is wider than the IUCD) passing through the endocervical canal and reaching the uterine fundus. In 2015, 15 health care professionals (HCPs) using the direct method reported improved patient comfort, improved success rates and similar ultrasound placement [17]. There is, however, a lack of quantitative data comparing the direct method with the standard method in terms of insertion pain and the ensuing tolerability and contraceptive effectiveness of the device.

The aim of this study was to compare the pain experienced during IUCD placement with both procedures (direct and standard methods) and to observe adverse effects and user satisfaction over 6 months.

\section{Methods}

\section{Study design and population}

This prospective open-label cohort study was conducted in France. General practitioners (GPs), gynaecologists and midwives using exclusively either the direct or the standard method were 
invited to participate. All HCP participants completed an online questionnaire about their IUCD insertion procedure practices and habits. The following data were collected: university and continuous education; number of years' experience of IUCD insertion; number of IUCD insertions performed per year; use of premedication or of a drug-free strategy such as inviting the woman to introduce the vaginal speculum herself or of using the lateral decubitus position (right or left lateral decubitus may improve the woman's comfort during a gynaecological examination [18]); and the use of a tenaculum or hysterometer. HCPs carrying out fewer than 10 IUCD insertions per year were excluded from the study.

All women consulting one of the participating HCPs for IUCD insertion between 15 June and 15 December 2016 were invited to participate. Women recruited by direct method users were included in the direct method group (DM group) and those recruited by standard method users were included in the standard method group (SM group). The only exclusion criterion was the use of a non-Tshaped IUCD.

The primary outcome was the pain experienced during IUCD insertion. Secondary outcomes were procedure failure rate, occurrence of immediate side effects, satisfaction with the procedure, and tolerability and effectiveness at 1 and 6 months.

Women received written information on the day of enrolment, explaining the two different insertion techniques and the possibility of a higher risk of IUCD failure or expulsion with the direct method, the purpose of the study, the data processing method and the possibility of recovering their own data at any point. Entering the study had no influence on the care given, especially on the choice of insertion technique (the study was only observational). The protocol was submitted to the institutional review board of Rennes University Hospital for approval (no. 16.55, 21/04/2016) and registered with the Commission Nationale de l'Informatique et des Libertés (no. 1935248v1, 13/04/2016), according to French law.

Neither the women nor the HCPs received any financial reward.

\section{Data collection}

All questionnaires were standardised and validated by the Department of Epidemiology and Public Health of Rennes University Hospital. Participating women completed two self-administered questionnaires alone on the day of enrolment. The first was filled in immediately before the procedure (i.e. in the waiting room) and comprised demographic characteristics, gynaecological and obstetric history, feelings of anxiety, and anticipated pain. The women were not asked about the phase of their menstrual cycle at the time of IUCD insertion, as this factor has been shown not to 
influence insertion pain [19]. The second questionnaire was filled in by the woman on returning to the waiting room immediately after the consultation and comprised questions about premedication (whether prescribed by the HCP or self-medication), consultation atmosphere (very soothing, quite soothing, stressful or very stressful), pain experienced during and after IUCD insertion (expressed using a standardised 100 mm VAS: 0=no pain, 100=worst imaginable pain), adverse events, success of the procedure and satisfaction with the procedure. The two questionnaires were sent to the principal investigator $(\mathrm{AB})$ in a stamped addressed envelope, ensuring data confidentiality.

Participating women were called or emailed up to five times by the principal investigator, 1 month and 6 months after the procedure, and the following data were collected: pain experienced and occurrence of side effects requiring medical advice during the month following insertion, 6 month continuation or motive for discontinuation, 6 month complications, and satisfaction with the IUCD.

\section{Statistical analysis}

Univariate analysis was performed using $\chi^{2}$ and Fisher's exact tests for qualitative variables and Student's $t$ test for quantitative variables. Multilevel multivariate analysis using a random intercepts model was performed to control for correlation induced by recruitment design. The criterion ‘insertion pain’ was analysed as a continuous variable using multivariate linear regression analysis. Observations with missing data were excluded from the analysis.

\section{Results \\ Population}

Of the 200 HCPs who were invited to participate, 61 completed the online survey. Four were excluded since they carried out fewer than 10 insertions per year, and a further six failed to recruit any women within the 6 month study period. The final number of participants was 51: 26 GPs, 12 gynaecologists and 13 midwives. Of these, 25 were recruited for the DM group and 26 for the SM group. The two recruiting groups were similar in size, sex ratio $(p=0.191)$, age $(p=0.313)$, education (years of experience; $p=0.066)$ and number of procedures carried out per year $(p=0.657)$.

According to the estimated activity of the participating HCPs, approximately 1500 women underwent IUCD insertion between 15 June and 15 December 2016. All women were invited to participate. Overall, 541 women who returned completed questionnaires were recruited. Six women did not meet the inclusion criteria, leaving 281 in the DM group and 254 in the SM group (Figure 1). HCPs from the DM group recruited between one and 36 women (mean 10.04, standard deviation [SD] 8.6) and HCPs from the SM group recruited between one and 29 women (mean 8.47, SD 8.1). 
The groups were similar with regard to baseline characteristics (Table 1). Mean previous pregnancy rates were 1.24 (SD 1.1) in the DM group and 1.26 (SD 1.1) in the SM group ( $p=0.815)$.

The IUCD insertion procedures are detailed in Table 1. Anticipated pain was higher in the SM group ( $p=0.031$ ). The use of premedication was more frequent in this group $(p<0.001)$ and was associated with anticipated pain in the study population as a whole $(p<0.001)$ and in the SM group $(p=0.029)$. The use of a drug-free strategy was more frequent in the DM group $(p<0.001)$. Some women received more than one premedication, more than one drug-free strategy, or even a combination of premedication and drug-free strategy. The use of a tenaculum and hysterometer was more frequent in the SM group $(p<0.001)$.

\section{Insertion pain: univariate and multivariate analyses}

Univariate analysis of VAS values showed less insertion pain in the DM group (median $13 \mathrm{~mm}$, mean 19.9 mm, SD 22.5) compared with the SM group (median $24 \mathrm{~mm}$, mean $33.4 \mathrm{~mm}$, SD 29.3) $(p<0.001)$ (Table 2, Figure 2). This was also true for the nulliparous women in the DM group (median 23 mm, mean 28.5 mm, SD 24.7) vs the SM group (median $53.5 \mathrm{~mm}$, mean $51.3 \mathrm{~mm}$, SD 27.3) $(p<0.001)$ (Figure 2). Age, parity, vaginal or caesarean delivery in the preceding 3 months, current breastfeeding, first experience of IUCD insertion, profession of the HCP and consultation atmosphere were also significantly associated with insertion pain (Table 2).

Multivariate analysis of insertion pain predictors indicated that use of the direct method was independently associated with less insertion pain by a VAS value of $8.3 \mathrm{~mm}$ (95\% confidence interval [CI] -14.3, -2.3). The number of previous vaginal deliveries, a vaginal or caesarean delivery in the preceding 3 months and a 'very soothing' consultation atmosphere were also independently associated with less pain. A history of IUCD insertion failure, high anticipation of pain, and the use of a tenaculum were independently associated with greater pain (Table 3).

\section{IUCD insertion: secondary outcomes}

Secondary outcomes are detailed in Table 4. Vasovagal symptoms occurred more frequently in the SM group ( $p=0.036)$. One woman in this group reported syncope $(p=1.0)$. In multivariate analysis the occurrence of vasovagal symptoms was correlated with the level of pain during insertion (odds ratio [OR] 1.03 [95\% CI 1.01, 1.04] per 10 mm VAS value increase). Other side effects were mild and rare. 
Nine insertion attempts failed: three (1.1\%) in the DM group and six (2.4\%) in the SM group $(p=0.322)$.

In the DM group, $87 \%$ of women were 'very satisfied' with the procedure vs $84 \%$ of women in the SM group ( $p=0.729$ ). Multivariate analysis identified the ‘very soothing' atmosphere of the consultation (OR 1.20 [95\% CI 1.13, 1.28]) and the low level of insertion pain (OR 1.04 [95\% CI 1.03, 1.05] per $10 \mathrm{~mm}$ VAS value decrease) as significant predictors of a high level of satisfaction.

\section{Follow-up at 1 month}

Response rates were good at 1 and 6 months. Pain during the first month was lower in the DM group than in the SM group $(p<0.001)$. The occurrence of adverse effects requiring medical advice was higher in the SM group (19\% vs $10 \%$ in the DM group; $p=0.003)$. Pain was the most common reason and was more frequent in the SM group $(p<0.001)$. There were no differences in the occurrence of other side effects: bleeding, device expulsion, mycosis, pelvic infection, nausea, hormonal symptoms and request for device removal (Table 4).

\section{Follow-up at 6 months}

The 6 month IUCD continuation rate was $89.4 \%$ in the DM group and $89.2 \%$ in the SM group $(p=0.936)$. One unintended pregnancy occurred in the DM group (due to a partially expelled device) vs none in the SM group ( $p=1.0)$. The woman chose to terminate the pregnancy. There were four cases (1.4\%) of pelvic infection requiring antibiotics in the DM group and seven cases (2.8\%) in the SM group ( $p=0.366)$. No uterine perforation or device migration was reported (Table 4). The 6 month IUCD satisfaction rate was $93.6 \%$ in the DM group vs $87.4 \%$ in the SM group $(p=0.019)$.

\section{Discussion}

\section{Findings and interpretation}

This observational study shows significantly less insertion pain with the direct method of IUCD insertion compared with the standard method, as well as fewer side and adverse effects up to 6 months following device insertion. Various explanatory factors may be assumed. The insertion technique itself may cause less pain, since the IUCD passes through the internal cervical os without the inserter (which is of greater diameter), and the physical contact of the fundus by the IUCD at placement is less severe with the direct method compared with the standard method. In addition, the direct method is a way of simplifying the insertion procedure with a shorter procedure duration and fewer intrauterine manipulations, thereby causing less pain [20]. Finally, with the direct method 
there is no need to use a hysterometer and, in most cases, a tenaculum, which have been described as the most painful stages of the procedure [21,22].

Use of the direct method may thus reduce the need for preventive analgesics: painkillers and other premedication were prescribed less often by HCPs using the direct method. These included potentially poorly tolerated drugs such as misoprostol and tramadol.

There was no increase in the incidence of either mild or severe adverse events with the direct method. The sample size was, however, too small to draw any conclusions about the safety of the technique.

\section{Strengths and weaknesses of the study}

The main strength of the study lies in the novelty of evaluating the direct method of IUCD insertion in a prospective comparative study of a large sample of women $(>500)$. The characteristics of our population, recruited throughout France, were similar to those found in IUCD users described in the literature $[23,24]$ : age $17-54$ years, about $55 \%$ over the age of 30 , one-third nulliparous, about $56 \%$ first-time IUCD users. We can thus assume that the study sample was representative of the target population. The DM and SM groups were similar and the follow-up rate was high.

Some limitations should, however, be mentioned. We decided to include HCPs who exclusively used only one of the two methods, to avoid overestimation of direct method pain: HCPs using both methods usually choose the direct method when anticipating a difficult insertion. This choice, however, somewhat limits the comparability of the direct and standard methods: HCPs using the direct method may be more fully committed to pain reduction, thus introducing a possible bias.

There were significant differences between groups in the use of pain control strategies, which might also have presented bias. The use of pain medications was less frequent in the DM group, which had lower pain scores, so the bias was in the opposite direction. The DM group more often used drug-free strategies, which may be a confounder; nevertheless, the efficacy of such strategies has never been demonstrated.

Moreover, the study was observational and non-randomised for ethical reasons, since there is no current evidence in the literature recommending the use of the direct method, and the recruitment was based on voluntary participation. 


\section{Similarities and differences in relation to other studies}

To our knowledge, no quantitative study of the direct method has been published to date. With the standard method, the reported VAS values for IUCD insertion pain vary considerably (18-60 mm) [6-11]. Predictors of pain identified in our study were similar to those found by others. Nulliparity and absence of vaginal deliveries are associated with greater pain [6-11,25], and less pain is experienced during the early postpartum period $[6,8,9]$. Anxiety and anticipated pain are associated with greater pain $[6,8,25]$. We found no data, however, about the influence of previous IUCD insertion failure. After controlling for a recent ( $<3$ months) obstetric event, breastfeeding did not significantly improve the model. Unlike larger studies, we found no association between breastfeeding and lower pain $[6,26]$, possibly owing to a lack of statistical power.

\section{Open questions and future research}

One unintended pregnancy occurred in the DM group due to a partially expelled device. This observation should encourage further studies to assess the contraceptive efficacy of IUCDs inserted with the direct method. It is known that low-lying and malpositioned copper-bearing IUDs are associated with a higher risk of pregnancy $[27,28]$ and device expulsion $[29,30]$ (while the efficacy of a low-lying LNG-IUS does not seem to be reduced [31]), but no threshold value has been defined to predict the risk. Systematic sonography is not recommended after a standard method IUCD insertion [1-3], but some authors consider that contraceptive efficacy cannot be guaranteed if the device is positioned $>2 \mathrm{~cm}$ from the fundus [3]. IUCDs often move, however, during the 3 months following insertion [32].

Most women in both groups were 'very satisfied' with the insertion procedure, including those having experienced a high level of pain or insertion failure. Although this may be interpreted as a marker of the quality of the consultation (good listening techniques, clear and comprehensible information, consideration of anxiety and pain), it also raises questions about the societal and cultural aspects of gynaecological care: women may feel that gynaecological or procreation-induced pain is inevitable and therefore may subsequently feel disinclined to complain.

\section{Conclusion}

Although larger tolerability studies are required, the direct method seems to be a safe and less painful procedure for IUCD insertion than the standard method, with a high continuation rate at 6 months and similar high efficacy. These new results thus strongly support the use of the direct method, pending confirmation by a randomised controlled trial. 


\section{Declaration statement}

The authors report no conflict of interest.

\section{Funding}

This research did not receive any specific grant from funding agencies in the public, commercial or not-for-profit sectors. 


\section{References}

[1] Committee on Practice Bulletins-Gynecology, Long-Acting Reversible Contraception Work Group. Practice bulletin no. 186. Long-acting reversible contraception: implants and intrauterine devices. Obstet Gynecol. 2017;130:e251-e269.

[2] National Institute for Health and Care Excellence. 2005, updated 2019. Long-acting reversible contraception. Clinical guideline CG30. Available from: www.nice.org.uk/guidance/cg30 (accessed 18 July 2018).

[3] Faculty of Sexual and Reproductive Healthcare. 2015. FSRH clinical guideline. Intrauterine contraception. Available from: www.fsrh.org/standards-andguidance/documents/ceuguidanceintrauterinecontraception (accessed 18 July 2018).

[4] Chanzy Waroquet A-L. Why do nulliparas no longer choose the IUD? Investigation among women. [Dissertation in French]. Grenoble: Université Joseph Fourier 2013.

[5] Drochon C. Tolerability of IUD insertion and IUD contraception in nulliparous women. [Dissertation in French]. Paris: Université Paris Diderot 2017.

[6] Hubacher D, Reyes V, Lillo S, et al. Pain from copper intrauterine device insertion: randomized trial of prophylactic ibuprofen. Am J Obstet Gynecol. 2006;195:1272-1277.

[7] Dijkhuizen K, Dekkers OM, Holleboom CAG, et al. Vaginal misoprostol prior to insertion of an intrauterine device: an RCT. Hum Reprod. 2011;26:323-329.

[8] Maguire K, Davis A, Rosario Tejeda L, et al. Intracervical lidocaine gel for intrauterine device insertion: a randomized controlled trial. Contraception. 2012;86:214-219.

[9] Allen RH, Raker C, Goyal V. Higher dose cervical 2\% lidocaine gel for IUD insertion: a randomized controlled trial. Contraception. 2013;88:730-736.

[10] Bednarek PH, Creinin MD, Reeves MF, et al. Prophylactic ibuprofen does not improve pain with IUD insertion: a randomized trial. Contraception. 2015;91:193-197.

[11] Wiebe ER. A comparison of the insertion pain associated with three different types of intrauterine device. Int J Gynaecol Obstet. 2015;129:172.

[12] Haute Autorité de Santé. 2017. Contraception in men and women [article in French]. Available from: www.has-sante.fr/portail/upload/docs/application/pdf/201502/contraception_fiches_memo_rapport_delaboration.pdf (accessed 18 July 2018).

[13] Gemzell-Danielsson K, Mansour D, Fiala C, et al. Management of pain associated with the insertion of intrauterine contraceptives. Hum Reprod Update. 2013;19:419-427.

[14] Pergialiotis V, Vlachos DG, Protopappas A, et al. Analgesic options for placement of an intrauterine contraceptive: a meta-analysis. Eur J Contracept Reprod Health Care. 2014;19:149-160. 
[15] Lopez LM, Bernholc A, Zeng Y, et al. Interventions for pain with intrauterine device insertion. Cochrane Database Syst Rev. 2015;7:CD007373.

[16] Savignac-Krikorian L, Benedini E, Bezanson E, Ruelle Y. Insertion of an intrauterine device: standard method and direct method [article in French]. Exercer. 2015;121:229-234.

[17] Savignac-Krikorian L. Direct method of IUD insertion. How? Why? [Master's thesis in French] Paris: Université Paris Descartes 2015.

[18] Grange-Cabane A. Lateral decubitus: pelvic examination from the patient's point of view [thesis in French]. Bordeaux: Université de Bordeaux 2014.

[19] Whiteman MK, Tyler CP, Folger SG, et al. When can a woman have an intrauterine device inserted? A systematic review. Contraception. 2013;87:666-673.

[20] Goldstuck ND, Matthews ML. A comparison of the actual and expected pain response following insertion of an intrauterine contraceptive device. Clin Reprod Fertil. 1985;3:65-71.

[21] Chor J, Bregand-White J, Golobof A, et al. Ibuprofen prophylaxis for levonorgestrel-releasing intrauterine system insertion: a randomized controlled trial. Contraception. 2012;85:558-562.

[22] Maguire K, Morrell K, Westhoff C, et al. Accuracy of providers' assessment of pain during intrauterine device insertion. Contraception. 2014;89:22-24.

[23] Haimovich S. Profile of long-acting reversible contraception users in Europe. Eur J Contracept Reprod Health Care. 2009;14:187-195.

[24] Gall B, Jouannic E. Les Français et la contraception. INPES 2007.

[25] Allen RH, Carey MS, Raker C, et al. A prospective cohort study of pain with intrauterine device insertion among women with and without vaginal deliveries. J Obstet Gynaecol. 2014;34:263-267.

[26] Chi IC, Wilkens LR, Champion CB, et al. Insertional pain and other IUD insertion-related rare events for breastfeeding and non-breastfeeding women - a decade's experience in developing countries. Adv Contracept. 1989;5:101-119.

[27] Anteby E, Revel A, Ben-Chetrit A, et al. Intrauterine device failure: relation to its location within the uterine cavity. Obstet Gynecol. 1993;81:112-114.

[28] Inal MM, Ertopçu K, Ozelmas I. The evaluation of 318 intrauterine pregnancy cases with an intrauterine device. Eur J Contracept Reprod Health Care. 2005;10:266-271.

[29] Petta CA, Faúndes D, Pimentel E, et al. The use of vaginal ultrasound to identify copper T IUDs at high risk of expulsion. Contraception. 1996;54:287-289.

[30] Shimoni N, Davis A, Westhoff C. Can ultrasound predict IUD expulsion after medical abortion? Contraception. 2014;89:434-439.

[31] Pakarinen P, Luukkainen T. Five years' experience with a small intracervical/intrauterine levonorgestrel-releasing device. Contraception. 2005;72:342-345. 
[32] Faúndes D, Perdigão A, Faúndes A, et al. T-shaped IUDs accommodate in their position during the first 3 months after insertion. Contraception. 2000;62:165-168. 
Table 1. Demographic characteristics of the study population and circumstances of device insertion.

\begin{tabular}{|c|c|c|c|c|c|}
\hline \multirow[t]{2}{*}{ Variable } & \multicolumn{2}{|c|}{ DM group $(n=281)$} & \multicolumn{2}{|c|}{ SM group $(n=254)$} & \multirow[t]{2}{*}{$p$-value } \\
\hline & $n$ & $\%$ & $n$ & $\%$ & \\
\hline \multicolumn{6}{|l|}{ Participants’ questionnaire } \\
\hline Age, in years, mean \pm SD (range) & $\begin{array}{l}32.03 \pm 7.7 \\
(17-52)\end{array}$ & & $\begin{array}{l}31.80 \pm 7.4 \\
(17-54)\end{array}$ & & 0.718 \\
\hline \multicolumn{6}{|l|}{ No. of previous pregnancies } \\
\hline 0 & 93 & 33.1 & 87 & 34.3 & 0.766 \\
\hline $1-2$ & 160 & 56.9 & 137 & 53.9 & \\
\hline $3-6$ & 28 & 10.0 & 29 & 11.4 & $y$ \\
\hline \multicolumn{6}{|l|}{ No. of previous vaginal deliveries } \\
\hline 0 & 121 & 43.0 & 104 & 40.9 & 0.839 \\
\hline $1-2$ & 134 & 47.7 & 128 & 50.4 & \\
\hline $3-6$ & 24 & 8.5 & 21 & 8.3 & \\
\hline \multicolumn{6}{|l|}{ No. of previous caesarean deliveries } \\
\hline 0 & 234 & 83.3 & 220 & 86.6 & 0.279 \\
\hline $1-2$ & 43 & 15.3 & 29 & 11.4 & \\
\hline $3-4$ & 2 & 0.7 & 4 & 1.6 & \\
\hline \multicolumn{6}{|l|}{$\begin{array}{l}\text { Gynaecological or obstetric event in the } \\
\text { preceding } 3 \text { months }\end{array}$} \\
\hline Vaginal delivery & 44 & 15.7 & 32 & 12.6 & 0.311 \\
\hline Caesarean delivery & 9 & 3.2 & 3 & 1.2 & 0.148 \\
\hline Abortion & 22 & 7.8 & 11 & 4.3 & 0.093 \\
\hline Breastfeeding & 35 & 12.5 & 29 & 11.4 & 0.712 \\
\hline Dysmenorrhoea & 80 & 28.5 & 72 & 28.3 & 1.0 \\
\hline History of sexually transmitted infection & 31 & 11.0 & 24 & 9.4 & 0.564 \\
\hline \multicolumn{6}{|l|}{ Type of HCP } \\
\hline GP & 122 & 43.4 & 91 & 35.8 & 0.093 \\
\hline Gynaecologist & 106 & 37.7 & 119 & 46.9 & \\
\hline Midwife & 53 & 18.9 & 44 & 17.3 & \\
\hline \multicolumn{6}{|l|}{ Type of IUCD } \\
\hline Copper-bearing IUD & 171 & 60.9 & 164 & 64.6 & 0.501 \\
\hline LNG-IUS & 98 & 34.9 & 83 & 32.7 & \\
\hline First IUCD insertion procedure & 160 & 56.9 & 140 & 55.1 & 0.675 \\
\hline Previous IUCD insertion failure & 5 & 1.8 & 7 & 2.8 & 0.446 \\
\hline Preliminary anxiety (VAS score) & $29.32 \pm 26$ & & $31.61 \pm 26.5$ & & 0.316 \\
\hline Anticipated pain (VAS score) & $37.41 \pm 24.8$ & & $42.22 \pm 26.3$ & & 0.031 \\
\hline Premedication & 156 & 55.5 & 195 & 76.8 & $<0.001$ \\
\hline NSAIDs & 58 & 20.6 & 83 & 32.7 & 0.016 \\
\hline Tramadol or nefopam & 1 & 0.4 & 14 & 5.5 & $<0.001$ \\
\hline Paracetamol & 13 & 4.6 & 9 & 3.5 & 0.529 \\
\hline Phloroglucinol & 97 & 34.5 & 108 & 42.5 & 0.056 \\
\hline Misoprostol & 0 & 0 & 25 & 9.8 & $<0.001$ \\
\hline Benzodiazepine & 2 & 0.7 & 8 & 3.1 & 0.055 \\
\hline Homeopathy or phytotherapy & 8 & 2.8 & 26 & 10.2 & 0.001 \\
\hline Combination of several drugs & 19 & 6.8 & 59 & 23.2 & $<0.001$ \\
\hline \multicolumn{6}{|l|}{ Consultation atmosphere } \\
\hline Very soothing & 197 & 70.1 & 195 & 76.8 & 0.021 \\
\hline Quite soothing & 82 & 29.2 & 53 & 20.9 & \\
\hline
\end{tabular}




\begin{tabular}{llllll} 
Stressful & 0 & 0 & 3 & 1.2 & \\
$\quad$ Very stressful & 0 & 0 & 0 & 0 & \\
HCP questionnaire & & & & & \\
Drug-free strategy & 176 & 62.6 & 57 & 22.4 & $<0.001$ \\
$\quad$ Patient insertion of speculum & 62 & 22.1 & 57 & 22.4 & 0.933 \\
$\quad$ Lateral decubitus & 91 & 32.4 & 7 & 2.8 & $<0.001$ \\
$\quad$ Hypnosis and sophrology & 42 & 14.9 & 29 & 11.4 & 0.293 \\
$\quad$ Full bladder & 10 & 3.6 & 7 & 2.8 & 0.608 \\
Use of tenaculum & & & & & \\
$\quad$ Systematic & 0 & 0 & 50 & 19.7 & $<0.001$ \\
$\quad$ Only if insertion attempt fails & 229 & 81.5 & 204 & 80.3 & 0 \\
$\quad$ Never & 52 & 18.5 & 0 & & \\
Use of hysterometer & & & & 55.5 & $<0.001$ \\
$\quad$ To measure uterine depth & 0 & 0 & 141 & 24.0 & \\
$\quad$ To determine cervical axis & 119 & 42.3 & 61 & 20.5 & \\
$\quad$ Never & 162 & 57.7 & 52 & & \\
\hline
\end{tabular}


Table 2. Level of pain at insertion, by insertion method and women's characteristics.

\begin{tabular}{|c|c|c|}
\hline Background characteristic & VAS score (mean \pm SD) & $p$-value \\
\hline \multicolumn{3}{|l|}{ Method of IUCD insertion } \\
\hline Direct method & $19.86 \pm 22.5$ & $<0.001$ \\
\hline Standard method & $33.35 \pm 29.3$ & \\
\hline \multicolumn{3}{|l|}{ Age, years } \\
\hline $17-25$ & $35.28 \pm 29.0$ & $<0.001$ \\
\hline$>25$ & $23.66 \pm 25.7$ & \\
\hline \multicolumn{3}{|l|}{ Parity } \\
\hline Nulliparous & $39.43 \pm 28.3$ & $<0.001$ \\
\hline Parous & $19.60 \pm 23.4$ & \\
\hline \multicolumn{3}{|l|}{ Vaginal deliveries } \\
\hline 0 & $39.94 \pm 28.4$ & $<0.001$ \\
\hline $1-6$ & $18.43 \pm 22.5$ & \\
\hline \multicolumn{3}{|l|}{ Caesarean deliveries } \\
\hline 0 & $26.41 \pm 26.7$ & 0.655 \\
\hline $1-4$ & $24.91 \pm 27.1$ & \\
\hline \multicolumn{3}{|c|}{$\begin{array}{l}\text { Gynaecological or obstetric event in the } \\
\text { preceding } 3 \text { months }\end{array}$} \\
\hline None & $29.59 \pm 27.5$ & \\
\hline Vaginal delivery & $8.95 \pm 13.4$ & $<0.001$ \\
\hline Caesarean delivery & $10.25 \pm 13.7$ & $<0.001$ \\
\hline Abortion & $30.91 \pm 28.0$ & 0.797 \\
\hline \multicolumn{3}{|l|}{ Currently breastfeeding } \\
\hline Yes & $14.94 \pm 20.8$ & $<0.001$ \\
\hline No & $27.78 \pm 27.2$ & \\
\hline \multicolumn{3}{|l|}{ Dysmenorrhoea } \\
\hline Yes & $28.94 \pm 27.7$ & 0.145 \\
\hline No & $25.05 \pm 26.2$ & \\
\hline \multicolumn{3}{|c|}{ History of sexually transmitted infection } \\
\hline Yes & $25.75 \pm 25.9$ & 0.920 \\
\hline No & $26.12 \pm 26.7$ & \\
\hline \multicolumn{3}{|l|}{ Type of IUCD } \\
\hline Copper-bearing IUD & $26.40 \pm 26.4$ & 0.843 \\
\hline LNG-IUS & $25.90 \pm 27.5$ & \\
\hline \multicolumn{3}{|c|}{ First IUCD insertion procedure } \\
\hline Yes $>1$ & $28.62 \pm 28.1$ & 0.006 \\
\hline No & $22.13 \pm 24.4$ & \\
\hline \multicolumn{3}{|c|}{ Previous IUCD insertion failure } \\
\hline Yes & $40.33 \pm 28.4$ & 0.107 \\
\hline No & $25.87 \pm 26.7$ & \\
\hline \multicolumn{3}{|l|}{ Type of HCP } \\
\hline GP & $31.07 \pm 27.9$ & 0.060 \\
\hline Gynaecologist & $24.16 \pm 26.2$ & \\
\hline Midwife & $20.27 \pm 23.8$ & \\
\hline \multicolumn{3}{|l|}{ Consultation atmosphere } \\
\hline Very soothing & $24.30 \pm 25.9$ & 0.010 \\
\hline Quite soothing & $31.55 \pm 28.4$ & \\
\hline Stressful & $32.50 \pm 33.2$ & \\
\hline \multicolumn{3}{|l|}{ Premedication } \\
\hline No & $21.18 \pm 29.3$ & \\
\hline
\end{tabular}


Yes $^{\mathrm{a}}$

Ibuprofen $^{\mathrm{a}}$

Tramadol $^{\mathrm{a}}$

Misoprostol $^{\mathrm{a}}$

${ }^{a}$ Compared with no premedication.
$28.65 \pm 27.7$

$31.82 \pm 30.0$

$49.13 \pm 35.1$

$33.32 \pm 28.9$
0.003

0.002

0.059

0.054 
Table 3. IUCD insertion pain: two-level multivariate linear regression (95\% CI) (479 observations).

\begin{tabular}{ll}
\hline Background characteristic & $\begin{array}{l}\text { Variation in VAS score } \\
(95 \% \mathrm{CI})\end{array}$ \\
\hline Insertion technique (ref. standard method) & $-8.3(-14.3,-2.3)$ \\
$\quad$ Direct method & $-0.1(-0.5,0.2)$ \\
Age (per 10 years) & $-0.2(-4.2,4.0)$ \\
No. of previous pregnancies (per occurrence) & $-4.2(-8.3,-0.3)$ \\
No. of previous vaginal deliveries (per occurrence) & \\
Gynaecological or obstetric event in the preceding 3 months & $-12.4(-18.5,-6.0)$ \\
$\quad$ Vaginal delivery & $-20.9(-34.4,-7.3)$ \\
$\quad$ Caesarean delivery & $-1.2(-9.6,7.2)$ \\
$\quad$ Voluntary interruption of pregnancy & \\
History of IUCD insertion (ref. previous successful insertion) & $2.6(-2.1,7.2)$ \\
$\quad$ First insertion & $16.4(2.2,30.3)$ \\
$\quad$ Previous insertion failure & $0.2(-0.9,1.4)$ \\
Initial anxiety (per 10/100 VAS score increase) & $2.0(0.8,3.2)$ \\
Anticipated pain (per 10/100 VAS score increase) & $14.9(-4.7,35.3)$ \\
Premedication (ref. no nefopam) & \\
$\quad$ Nefopam & $-7.3(-12.2,-2.7)$ \\
Consultation atmosphere (ref. quite soothing, stressful or very stressful) & \\
$\quad$ Very soothing & $16.0(2.7,29.2)$ \\
Use of tenaculum (ref. never) & $10.7(1.6,19.8)$ \\
$\quad$ Systematic &
\end{tabular}


Table 4. Secondary outcomes.

\begin{tabular}{|c|c|c|c|c|c|}
\hline & \multicolumn{2}{|c|}{$\begin{array}{l}\text { DM group } \\
(n=281)\end{array}$} & \multicolumn{2}{|c|}{$\begin{array}{l}\text { SM group } \\
(n=254)\end{array}$} & \multirow[t]{2}{*}{$p$-value } \\
\hline & $n$ & $\%$ & $n$ & $\%$ & \\
\hline \multicolumn{6}{|l|}{ Day of device insertion } \\
\hline Vasovagal symptoms & 42 & 14.9 & 60 & 23.6 & 0.036 \\
\hline Cramps & 11 & 3.9 & 4 & 1.6 & 0.124 \\
\hline Urinary symptoms & 0 & 0 & 1 & 0.4 & 0.476 \\
\hline Insertion failure & 3 & 1.1 & 6 & 2.4 & 0.322 \\
\hline Pain during first week & & & & & 0.338 \\
\hline No pain & 110 & 39.1 & 83 & 32.7 & $->$ \\
\hline Mild pain & 59 & 21.0 & 65 & 25.6 & - \\
\hline Moderate pain & 61 & 21.7 & 55 & 21.7 & - \\
\hline Severe pain & 31 & 11.0 & 34 & 13.4 & - \\
\hline \multicolumn{6}{|l|}{ Pain during first month } \\
\hline No pain & 205 & 73.0 & 163 & 64.2 & - \\
\hline Mild pain & 30 & 10.7 & 21 & 8.3 & - \\
\hline Moderate pain & 19 & 6.8 & 24 & 9.4 & - \\
\hline Severe pain & 6 & 2.1 & 26 & 10.2 & - \\
\hline \multicolumn{6}{|l|}{1 month follow-up } \\
\hline Pain & 5 & 1.8 & 24 & 9.4 & $<0.001$ \\
\hline Bleeding & 11 & 3.9 & 19 & 7.5 & 0.094 \\
\hline Device expulsion & 1 & 0.4 & 2 & 0.8 & 0.608 \\
\hline Device removal & 3 & 1.1 & 6 & 2.4 & 0.323 \\
\hline Mycosis & 1 & 0.4 & 2 & 0.8 & 0.608 \\
\hline Infection & 0 & 0 & 2 & 0.8 & 0.228 \\
\hline Vasovagal symptoms & 1 & 0.4 & 4 & 1.6 & 0.199 \\
\hline Hormonal symptoms & 0 & 0 & 2 & 0.8 & 0.228 \\
\hline \multicolumn{6}{|l|}{6 month follow-up } \\
\hline Device expulsion & 4 & 1.4 & 2 & 0.8 & 0.689 \\
\hline Device removal & 24 & 8.5 & 23 & 9.1 & 0.678 \\
\hline Pregnancy & 1 & 0.4 & 0 & 0 & 1.0 \\
\hline Infection & 4 & 1.4 & 7 & 2.8 & 0.366 \\
\hline Perforation & 0 & 0 & 0 & 0 & 1.0 \\
\hline
\end{tabular}


Figure 1. Flow chart.

Figure 2. Pain scores in women undergoing IUCD insertion by the direct method or the standard method. 
$25 \mathrm{HCPs}$ using the direct method
26 HCPs

using the standard method

About 1500 women underwent IUCD insertion

3 insertion failures

17 lost to follow-up

13 lost to follow-up
281 in the DM group completed the questionnaires
6 excluded 2 non-T-shaped IUCDs, 1 absence of insertion attempt, 2 other HCPs, 1 unknown HCP
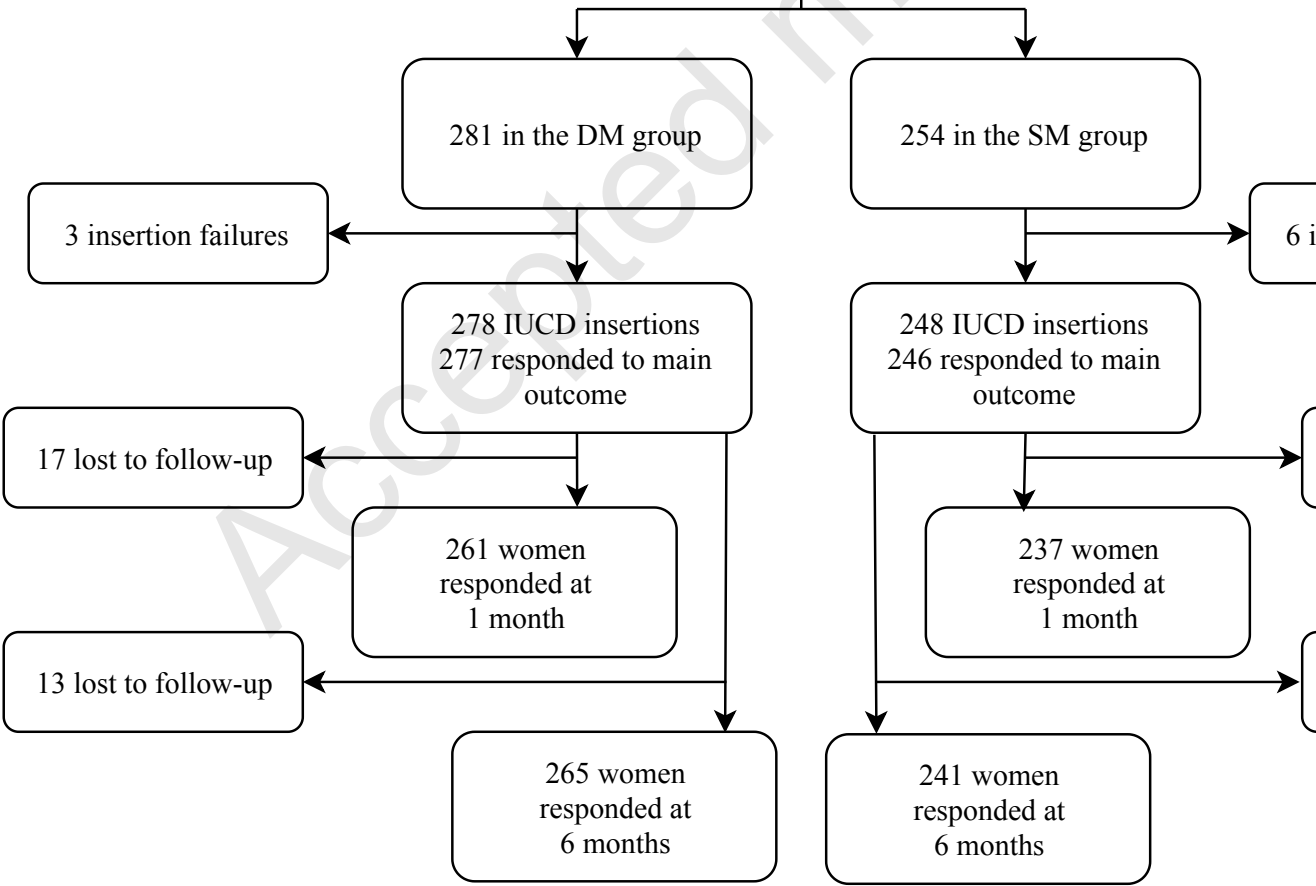

11 lost to follow-up

7 lost to follow-up 


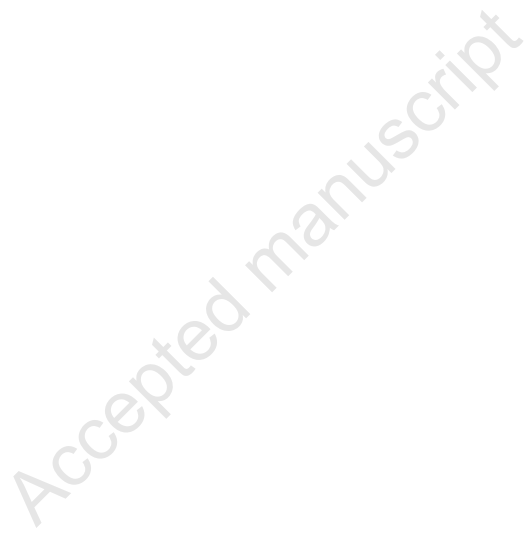

